\title{
The Gender Pay Gap in Nigeria: Causes and Remedies
}

\author{
Fapohunda, Tinuke. M. \\ Department of Industrial Relations and Public Administration \\ Lagos State University Ojo. Nigeria \\ Email: tkfap@yahoo.com
}

Doi:10.5901/mjss.2013.v4n2p211

\begin{abstract}
Pay gap between males and females is a major policy concern in national developmental discourse. The paper examines the causes of gender pay gap in Nigeria. The theories proposed in literature suggest three principal causes: differences in human capital, crowding discrimination, and other forms of discrimination. This paper reviews studies on the pay disparities and examines the many explanations for the disparities. It employs both primary and secondary data sources from the Federal Office of Statistics (FOS) and the survey conducted by the researcher. The population for the study comprised teachers, medical doctors and journalists in three local government areas in Lagos Nigeria. Respondents were randomly selected from each of the three professional bodies. 240 questionnaires were administered across of which 185(77 \%) made up of 82 (44.3\%) females and 103 (55.7\%) males were returned in usable condition. Mean comparisons were used to determine significance of differences between the pay of male and female respondents. To reduce the disparities in pay it recommends actions like legislative measures, general recommendations, monitoring procedures and support for low-paid occupations.
\end{abstract}

Keywords: Gender, Pay, Gap, Causes, Remedies.

\section{Introduction}

Gender pay gap has to do with the relative differences in the average gross earnings of men and women within an economy. UNDP (2009) observes that between 1985 and 2008, inequality in Nigeria worsened from 0.43 to 0.49 , placing the country among those with the highest inequality levels in the world. Despite its vast resources, Nigeria ranks among the most unequal countries in the world. The poverty problem in the country is partly a feature of high inequality which manifests in highly unequal income distribution and differential access to basic infrastructure, education, training and job opportunities. In the past three decades, women in Nigeria have made notable gains in participation in the workplace including increased labour force participation, substantial gains in educational attainment, employment growth in higher paying occupations, and significant gains in real earnings. However, notwithstanding these gains, there is still pay gap between males and females across almost all occupations in favour of men. The Nigeria Human Development Report (2009) highlights agreement in principle on the desired path of development among independent development experts and Nigerian government officials. The declared goal of "growth with equity," is however, faced by many obstacles to its implementation. There is consensus that there are gender pay differences against females and in favour of males. Equal pay legislation was introduced in the Nigeria over 40 years ago. Gender equality legislation was further reinforced by the 2007 Gender Equality Duty applying to all public bodies and aspects of the 2010 Equality Act. However, Nigeria still has a long way to go in order to achieve equality in workplace. The UNDP (2009) indicates that Nigeria's gender pay gap is one of the highest in the world and females are under-represented in the higher paid, more powerful positions.

The lower pay for women has negative impact on the children as well as the family because of the financial instability.Employees are motivated to perform better when rewarded adequately. They set expectations about rewards to be received, if certain levels of performance are achieved and these expectations determine goals or levels of performance for the future. Organization's pay structure must, therefore be equitable and consistent without gender discrimination. This paper seeks to explore causes of and remedies to the gender pay gap in Nigeria. 


\section{Literature}

\subsection{Causes of Gender Pay Gap}

Several studies have analyzed the sources of earnings differentials between men and women. The evidence tries to explain the pay gaps in terms of observable individual characteristics (such as education, experience, occupation, and, sometimes, motivation, expectations, and field of study), and/or horizontal and vertical segregation in employment. Blau, Ferber and Winkler (1998) affirms that not only occupation, age, experience, education, and time in the workforce, but also childcare, average hours worked, grades while in college are possible explanatory factors. Blau, Lawrence and Kahn (2006) notes that, while the overall size of the pay gap has decreased somewhat over time, the proportion of the gap that is unexplained by human capital variables is increasing.However, OECD (2009) affirms that while these factors explain large parts of the gender pay gaps, analysis generally leave a portion of gender pay gaps unexplained.

The unexplained part of the gender pay gap reflects the influence of unobservable factors, including discrimination against women in the labour market. It is difficult to pin down precisely its contribution to the size of the pay gap because it is rarely directly observable and there are measurement problems. Bergmann (1984) found that the gender pay gap can only be partially explained by human capital factors and "work patterns." Admittedly, gender pay gaps, particularly at higher earning, partially reflect past education and labour market patterns but earnings differences also relate to a range of often inter-related factors including the scope to reconciling work and family life as well as discrimination and occupational segregation.

A greater percentage of women than men tend to work part-time which obviously pays less than full-time work. Also more women than men tend to leave the labour force for issues such as child birth, child care and elderly care. In addition, Mason (1995) notes that pay appears to be more important to men than to women. Women, especially working mothers, tend to value policies that are family friendly in the workplace than men. Very often, women may value non-pay benefits more than men do and so prefer to take a greater portion of their compensation in the form of health insurance and other fringe benefits.

The Gender Pay Gap is a resultant effect of several factors which can be summarised as:

(i) Occupational segregation - Occupational segregation refers to the way that some jobs are dominated by men, and other jobs by women. Women tend to be concentrated in fewer occupations compared with men. As Soetan (2002) observes, $50 \%$ of the women in Nigeria work in 7 occupations only. Women tend to work in clerical occupations, sales, health care, social care and teaching professions; they are under-represented in managerial jobs, physical, mathematics, science and engineering professions as well as in manual and production jobs. In the last few decades women have made great strides in narrowing the pay gap within professions and increasing their numbers within traditionally male-dominated fields. Ojo (1998) asserts that occupational segregation appears to be more pronounced for low-skilled workers and for women with children. In agreement with this OECD (2009) notes that workers with higher education are found in a much larger number of occupations than less educated workers while mothers are more likely than women without children to work as service workers and sales workers. This might be the result of self-selection of mothers into occupations that are more compatible with family responsibilities or related to some employers being less likely to offer mothers career and employment opportunities. Fathers also tend to reinforce their concentration in occupations where men are over-represented, which are in general more likely to be management positions with higher earnings. Though some of the differences in occupational choices among women and men are due to different preferences others may not be. Oloko (2001), Okpara (1997) and Weaver (1998) suggest that predominantly female occupations pay less even in spite of individual and workplace characteristics.

There is also a "vertical" component to occupational segregation: women are under-represented in managerial jobs, especially at the most senior levels. Women also are less likely to reach the upper rungs of the corporate ladder. Women especially in the private sector in Nigeria tend to be concentrated in entry or middle-level positions. UNDP (2009) affirms that on the average women held 9.2\% of board seats in Nigeria in 2007.

Gender differences in career progression is due to factors like higher exit rates, higher incidence of part-time, higher incidence of entry and exit spells, possibly differences in personality traits.

Blau, Ferber and Winkler (2001)confirms that though occupational segregation is declining pay differentials between men and women remain substantial though in comparison to men's pay women's pay has improved due to a decrease in occupational segregation. They argue that the gender pay difference will decline modestly and that the extent of discrimination against women in the labour market seems to be decreasing. 
(ii) Workplace flexibility - Solberg \& Laughlin (1995) found that occupational selection is a primary determinant of the gender pay gap. Women tend to choose less-paying occupations because they provide flexibility to better manage work and family. Women are less likely than men to choose high paying careers because they are worried about combining family and career. Findings as regards gender and workplace flexibility are however different. For instance, Witt (1992) and Weaver (1998) found that male-dominated jobs in fact have more flexibility and autonomy than female-dominated jobs and allow one to more easily leave work to tend to a sick child. Also Boushey (2007) suggests that men actually have more access to workplace flexibility and that it is a myth that women choose lesspaying occupations because they provide flexibility to better manage work and family. But Blau, Lawrence and Kahn (2006) as well as Wood et al. argue that though free choice factors are significant, they leave large portions of the gender earnings gap unexplained.

(iii) Hours worked - Becker (1993) posits that traditional division of labour in the family disadvantages women in the labour market because they devote relatively more time and effort to housework and have less time and effort available for performing market work. The OECD (2009) indicates that women work fewer hours because responsibilities for child-rearing and other unpaid household work are still unequally shared among partners. Mason (1995) observes that arising from sex differences in hours worked, the hourly earnings gap is a better indicator of gender disparity in earnings than the annual figure especially because employees who work more hours also tend to earn more per hour. Hours worked therefore account for a part of the gender pay gap.

(iv) Direct discrimination - Discrimination by employers tends to steer women into lower-paying occupations and men into higher-paying occupations. Opeke (2002) affirms that there are statistically significant pay differences between jobs defined as male and female, which implies that salary allocation is affected by gender-based discrimination, due to occupational stereotyping and the devaluation of the work typically done by women. Again women in jobs defined as male such as science and engineering are sometimes affected by bias and outmoded institutional structures. Smith, James and Ward (1999) found evidence of differential treatment of senior women which included differences in salary among others with women receiving less despite professional accomplishments equal to those of their male colleagues. Work by men is often subjectively seen as higher-quality than objectively equal or better work by women compared to how an actual scientific review panel measured scientific competence. The Smith, James and Ward (1999) results indicates that female scientists need to be at least twice as accomplished as their male counterparts to receive equal credit.

(v) Gender Stereotypes - Gender stereotypes are the driving forces behind occupational segregation because they influence men and women's educational and career decisions. In Nigeria there are widely shared cultural beliefs that men are more socially valued and more competent than women at most things, as well as specific assumptions that men are better at some certain tasks while women are better at others. These gender status beliefs affect the assessments people make of their own competence at career-relevant tasks. Oloko (2001) notes that specific stereotypes affect women's and men's perceptions of their abilities to the extent that men assess their own task abilities higher than women performing at the same level. These biased self-assessments tend to shape men and women's educational and career decisions.

The OECD (2010) affirms that women's labour market behaviour is influenced by learned cultural and social values that may be thought to discriminate against women by stereotyping certain work and life styles as "male" or "female". Women's educational choices are determined partly by expectations that some types of employment opportunities are not available to them, and by gender stereotypes that are prevalent in society.

(vi) Bias Favouring Men- Oloko (2001) and Bommer (2003) observe that members of low-status groups like women tend to be subject to negative stereotypes and attributes concerning their work-related competences while members of high-status groups like men are more likely to receive favourable evaluations about their competences, normality, and legitimacy. Even women and minority raters tend to be susceptible to systematic gender biases.

(vii) Anti-female bias and Perceived role Incongruence- There are pervasive tendencies to devalue women's work and prejudice against women in male-dominated roles which are incongruent for women. Collinson and Collinson (2000) affirms that women who enter high-status, male-dominated work settings are evaluated more harshly and meet with more hostility than equally qualified men. Virginia (2001) adds that the "think managers - think male" concept indicates gender stereotypes and status beliefs that associate greater status worthiness and competence with men than women. Okpara (1997) notes that gender status beliefs influence the assertiveness of men and women, the attention and evaluation their performances receive, and the ability attributed to them on the basis of performance. 
Oloko (2002) affirms that perceived incongruity between the female gender roles and leadership roles leads to two forms of prejudice. The first perceives women less favourably than men as potential leaders and the second evaluates behaviour that fulfils the prescriptions of leadership roles less favourably when it is enacted by a woman. Consequently, attitudes are less positive toward female than male leaders and potential leaders. It becomes more difficult for women to become leaders and to achieve success in leadership roles. When women are acknowledged to have been successful, they are less liked and more personally derogated than equivalently successful men. Assertive women who display masculine traits are seen as violating prescriptions of feminine niceness and are penalized for violating the status order.

(viii) Maternity Leave - Sowell (1984) asserts that most of the gender pay gap is due to marital status not glass ceiling discrimination. Sowell adds that earnings for men and women of the same basic description (education, jobs, hours worked, marital status) is essentially equal. Bommer (2003) observe that even in relatively gender-equal countries like Sweden, where parents are given 16 months of paid parental leave irrespective of gender, fathers take on average only $20 \%$ of the 16 months of paid parental and choose to transfer their days to their partner. In Nigeria there is a significant degree of the unequal contributions made by each partner to child raising which negatively affects the average pay for females.Added to maternity leave, marriage in general leaves women with more household labour than the males.Soetan (2002) notes that in Nigeria married women earn $68.3 \%$ as much as married men while women who have never married earn $74.6 \%$ of their unmarried male counterparts' earnings. The economic risk and resulting costs of a woman possibly leaving jobs for a period of time or indefinitely to nurse a baby is cited by many to be a reason why women are less common in the higher paying occupations and upper management.

(ix) Motherhood penalty and men's marriage premium - The OECD (2010) indicates that there is a significant impact of children on women's pay. Correll and Bernard (2007) found that female applicants with children were significantly less likely to get hired and if hired would be paid a lower salary than male applicants with children notwithstanding similarities in qualification, performance and other relevant characteristics. Correll and Bernard also found in another study that actual employers discriminate against mothers when making evaluations that affect hiring, promotion, and salary decisions, but not against fathers. They argue that the motherhood role exists in tension with the cultural understandings of the "ideal worker" role and this leads evaluators to expect mothers to be less competent and less committed to their jobs. Anderson, Binder and Krause (2003) reports a significant motherhood penalty on pays and evaluations of workplace performance and competence even after statistically controlling for education, work experience, race, whether an individual works full- or part-time, and a broad range of other human capital and occupational variables.

(x) Gender differences in perceived pay entitlement- The gender pay gap is related to gender differences in perceptions of pay entitlement. Perceptions of pay entitlements differ for men and women. Men are more likely to feel worthy of higher pay while women's sense of pay entitlement is depressed. Women's beliefs about their relatively lower worth and their depressed pay entitlements reflect their lower social status such that when women's status is raised, their pay entitlement rises as well. The argument is that the perceptions perpetuate nonperformance related pay differences between women and men. Williams et al (2010) found that men and to a lesser extent women assign higher salaries to men than women based on automatic stereotypic associations. They argue that observations of men as higher earners than women has led to a stereotype that associates men (more than women) with wealth, and this stereotype itself perpetuates the pay gap at both conscious and non-conscious levels.

(xi) Negotiating Salaries - Situational factors assumed to influence salary negotiation include knowledge of the competitive rate of pay for a task; consciousness of gender stereotypes about negotiation and negotiating on one's own behalf, versus negotiating anonymously or on behalf of someone else. Sowell (1984) suggests that women were less likely than men to negotiate when the behaviour was labelled as "negotiating" but equally likely when the behaviour was labelled as "asking". Olagbegi and Afolabi (2004) found that males are eight times more likely to negotiate starting salaries and pay than females. Again more than twice as many women as men felt "a great deal of apprehension" about "negotiating. Stevens et al (1993) found that men on the average negotiate more aggressively than women. However Gerhart and Rymes (1991) found that though women did not negotiate less than men they obtain lower monetary returns from negotiations. 


\section{Theoretical Framework}

\subsection{The Human Capital Theory}

Arrow (2003) asserts that the core thesis of human capital theory is that peoples' learning capacities are comparable to other natural resources involved in the production process and when the resource is effectively exploited the results are profitable both for the enterprise and for society as a whole. Men and women often come to the labour market with different tastes and with different qualifications, such as education, formal training, experience, and other productivityrelated characteristics which could cause women to earn less and to be concentrated in different occupations. The theory assumes that workers and employers are rational and that the labour market functions efficiently. On the labour supply side the theory posits that workers seek out the best paying jobs based on their personal endowments, constraints and preferences. Employers always seek to maximize profit by maximizing productivity and minimizing costs.

The level of female human capital in terms of what they bring to the labour market and what they acquire after

joining has been low. Family responsibilities also cause women to gain less experience than men. Whereas men come to the labour market with more of the productivity related characteristics they get higher pays. The relationship between women's education, experience and their occupation is bi-directional in nature. Therefore women choose occupations that are relatively low in starting pay, returns to experience and penalties for temporary withdrawal from the labour force i.e. jobs with flexibility in terms of entry and working hours. In view of the historical trends in human capital characteristics, male-female earnings disparity is explained. However, since the educational gap between males and females in the country is closing the effect of education on pay disparities should be reducing. between

The Federal Office of Statistics (2012) reports that $57 \%$ of first degree graduates from Nigerian universities

2008 and 2011 were females. However, women are still more likely to take time off work for child bearing reasons. In addition, Becker (1993) suggests that when employed fulltime; women are more likely to expend more effort on unpaid housework than on their market work. The human capital theory suggests that due to traditional family roles women tend to have a weaker attachment to the labour force and so they acquire less of valuable on-the-job training. Therefore women's domestic responsibilities as cited are the major reason for lower earnings in female occupations and for women in general.

\subsection{The Overcrowding Theory}

This assumes that on the average, differences exist in productivity, skills and experience etc. of distinct groups of workers and that there is high search and information association with recruitment and promotion decisions. The argument here is that it is rational for employers to discriminate against groups of workers (e.g. women) when differences on the average between the abilities of persons from different groups cost less to sustain than the decision making costs associated with identifying suitable workers of either sex. This explains how certain jobs are almost exclusively male dominated even when several individual women possess greater ability and higher levels of education than many individual men.

Bergmann (1974) asserts that stereotypes and societal perceptions on what is "normal" divide labour markets into two (for males and females) where the individuals are perfect substitutes. Acceptable occupations for them tend to emphasize stereotypical female characteristics so they tend to be crowded into these fields and for those who do not choose such traditional female occupations, crowding becomes a form of discrimination. With discrimination the market is divided into that for those discriminated against and that for the preferred co-workers and demand is no longer the same for both groups. Jobs in the separate markets are characterized by a restricted supply of labour and pays increase for one group. Those in the second group must crowd into a restricted number of positions to remain in the market. Pay differentials result when relative to respective supplies, one demand exceeds the other. More females are "crowded" into a market that faces less demand, relative to the supply of labour in that market.

While pay differentials also exist in male-dominated occupations, traditional female occupations reflect an overall discrimination effect simply because they are female dominated. Macpherson and Hirsch (1995) found that both men and women earn less as an occupation becomes more "female." The concentration index (i.e. how female dominated an individual's occupation is) has a negative impact on pays. The more female-dominated an occupation is, the less the average worker in that occupation earns. "Women's work" compensates with lower pays and salaries on average. Therefore though education is important in determining which segment of the labour market women workers are able to gain access, it does not guarantee elimination of pay discrimination. In Nigeria women workers are often positioned at a 
disadvantage partially because of low economic growth and human development, but also due to cultural and social values too which reinforce economic insecurities faced by women.

\subsection{The Discrimination Theory}

There is labour market discrimination anytime men and women of equal productivity and aspirations are treated differently in hiring, retention, training, and promotion practices. According to Becker (1993) on the demand side, there is labour market discrimination when two equally qualified individuals are treated differently solely on the basis of their gender. Where there is no discrimination, profit-maximizing employers in a competitive labour market will pay workers based on their productivity. Where discrimination exists, it adversely affects the economic status of women by bringing about differences in pay between men and women not accounted for by differences in productivity-related characteristics. Such inequality may occur when women are paid less than their marginal products as a result of discrimination or when labour market discrimination directly lowers women's productivity and their pay.

Forms of labour market discrimination vary. One is the "taste for discrimination" model or human capital choice which with respect to gender involves the pure dislike of working with someone of the opposite sex. This may be from employers, other employees who refuse or customers who are consequently willing to pay something either directly by way of a reduced income to be associated with certain persons rather than others.

Another variation of labour market discrimination is that arising from a market failure like imperfect information. Blau, Ferber and Winkler (1996) affirm that the model of statistical discriminationassumes that employers and/or consumers face imperfect information and uncertainty regarding individuals' potential productivity. In taking hiring or promotional decisions, they project their "average" beliefs about a particular group onto individual applicants who belongs to such groups. Therefore, individuals are discriminated against because the broader group to which they belong is believed to share some undesirable, stereotypic characteristics. Consequently, qualified applicants are erroneously excluded from employment. Employers may believe that females have less expected employment life than their male counterparts and decide not to grant them the same opportunities of firm-specific training, job assignments, or promotion available to males. Based for example on the perception that on average, married women are more likely to withdraw from the labour force at some point than men are to have children, employers may doubt the returns from training or promoting married women and so be less willing to do so.

Even though this type of discrimination is not easily measurable it eventually becomes an institutional factor which has adverse effects on women's economic status by lowering their incentives to continue schooling, participate in training programmes, remain continuously in the labour market, and so on. "Discriminatory socialization" at different levels also affect choices made by women and their access to educational and vocational training. The choices are determined by women's ability to meet familial and social obligations while working, and this strongly affects their decisions to enter the labour force. For instance, Hausa women in Nigeria are constrained by seclusion norms to home-base activities in the informal sector.

Human capital investment must therefore recognize the gendered aspects to educational and vocational training.

In sum, the literature review and the theoretical explanations for gender pay gap have to do with effects of individual human capital characteristics; occupation (specifically how female-dominated an occupation is) and a residual, which largely comprises discrimination effects. This study therefore postulates these hypotheses that:

1. Human Capital Variables and will have positive coefficients for males and females.

2. The Coefficients for Marital and family choice variables be positive for males and negative for females.

3. The discriminatory effects of crowding on wages will be negative for both sexes.

\section{Methodology}

This study employs both primary and secondary data sources. Secondary data was in form of cross-sectional data from the General Household Survey (GHS) conducted yearly by the Federal Office of Statistics (FOS). Primary data was obtained from the survey conducted by this researcher between in August and October 2012. The population for this study comprised teachers, medical doctors and journalists in four local government areas in Lagos Nigeria. Respondents were randomly selected from each of the three professional bodies of the doctors, teachers and journalists. 240 questionnaires were administered of which 185(77 \%) made up of $82(44.3 \%)$ females and $103(55.7 \%)$ males were returned in usable condition. Mean comparisons were used to determine significance of differences between the pay of male and female respondents. 


\section{Results}

Table 1 Actual Pay of Male and Female Professionals

\begin{tabular}{l|c|c|c|c}
\hline & & & Salary $=\mathrm{N}=$ & Salary $=\mathrm{N}=$ \\
\hline Occupation & Male & Female & Male & Female \\
\hline Doctors & 42 & 17 & $=\mathrm{N}=2,056,000$ & $=\mathrm{N}=1,904000$ \\
\hline Journalists & 48 & 26 & $=\mathrm{N}=1,408,000$ & $=\mathrm{N}=1,296,000$ \\
\hline Teachers & 13 & 39 & $=\mathrm{N}=1,299,200$ & $=\mathrm{N}=1,187,200$ \\
\hline Total & 103 & 82 & & \\
\hline
\end{tabular}

Table 1 gives the average actual salary of male and female professionals in the three occupations. The indication is that male doctors had a mean annual pay of $=\mathrm{N}=2,056,000$, while their female counterparts only had a mean annual pay of $=\mathrm{N}=1,904,000$ giving an annual difference of $=\mathrm{N}=152,000$. For the journalists there was a mean of $=\mathrm{N}=1,408,000$ for males as against $=\mathrm{N}=1,296,000$ for the while females resulting in a difference of $=\mathrm{N}=112,000$. Again for the teachers (a profession dominated by females) the mean annual pay for males was $=\mathrm{N}=1,299,200$ and that of the females was $=\mathrm{N}=1,187,200$ giving a difference of $=\mathrm{N}=112,000$ annually.

$72(38.9 \%)$ of the respondents indicate that gender pay gap is due to the effects of different reward structures to human capital and differences in the average percentage of females in the individual's occupation. $52(28.2 \%)$ indicate that gender the pay gap is due to crowding discrimination while thought it was due to sheer stereotypes and overt discrimination.

Table 2: Gender Pay Disparity and Human Capital Variables

Male

Female

\begin{tabular}{l|c|c|c|c|c|c}
\hline Variable & $\mathrm{N}$ & $\mathrm{R}$ & $\mathrm{p}<$ & $\mathrm{N}$ & $\mathrm{r}$ & $\mathrm{p}<$ \\
\hline Education & 103 & $.48^{* *}$ & .005 & 82 & $.66^{* *}$ & .002 \\
\hline Work Experience & 103 & $.32^{* *}$ & .005 & 82 & $.57^{* *}$ & .000 \\
\hline Length of Service & 103 & $.48^{* *}$ & .006 & 82 & $.51^{* *}$ & .001 \\
\hline Hours worked & 103 & $.56^{* *}$ & .003 & 82 & $.48^{* *}$ & .005 \\
\hline On the job training & 103 & $.67^{* *}$ & .001 & 82 & $.43^{* *}$ & .007 \\
\hline
\end{tabular}

Table 2 present Pearson Correlations of gender and human capital variables. Results of the mean comparison and t-test between males and females indicate gender pay disparity. It also shows a significant relationship between level of pay, gender, and human capital variables of education, work experience, length of service to an organization, opportunity for on the job training and hours worked. These variables explain the causes of pay disparities between males and females in the country. The human capital variables gave highly significant, positive coefficients for both men and women and therefore affirm the first hypothesis that human capital variables will have positive coefficients for males and females. Level of education was significant in explaining pay gap. The average level of education for females is lower than that of males. For instance the number of males with university degrees was higher than the females. This confirms the observations of Okpara (1996) and Opeke (2002) that until recently, females in Nigeria were not encouraged to go to school, and those who went were directed towards traditional female occupations like teaching, nursing, and clerical occupations while the males were encouraged to go into more lucrative occupations, such as medicine, engineering, business, accounting, and banking. Differences in work experience between men and women are very relevant factors of gender paydisadvantage against women in Nigeria. The results show that experience was clearly related to the gender pay gap. Females often have more career interruptions than men and, thus, less experience and expertise. Management decisions on promotion of females may also be based on stereotypes about career interruptions and the lack of experience of female workers. This may have contributed to the salary gender gap among the respondents surveyed. 


\section{Marital and Family Choices}

Table 3: Correlation of Marital and family choice variables for males and females

\begin{tabular}{|l|c|c|c|c|}
\hline Independent Variable & Coefficient & T-stat & Coefficient & T-stat \\
\hline (Constant) & $-52,723.18$ & $-20.261^{* * *}$ & $26,122.12$ & $11.941^{\text {*** }}$ \\
\hline Children & 599.15 & 1.111 & 516.35 & $1.362 \cdot$ \\
\hline Marriage & $3,422.24$ & $3.122^{\prime \prime}$ & 866.72 & $1.322 \cdot$ \\
\hline Flexibility & -55.97 & $-3.163^{\prime \prime}$ & -98.80 & $-8.218^{\prime \prime}$ \\
\hline
\end{tabular}

The results suggest that earnings drop significantly with child bearing for females but for males the reverse is the case. Though the effect from this variable is highly significant for females and not for males the results are still consequential and rational. Marital and family choice variables have positive coefficients for males and negative coefficients for females. By tradition women are seen as the primary domestic homemakers and caregivers. Though these roles are becoming less stringent with time, where children are involved the tradition is still very much in place. Consequently, females have often had to either reduce their volume of work or quit working altogether during the childbearing years bringing about a loss of income which men try to compensate for by earning more. Women workers in pay employment are concentrated mostly in teaching, nursing and secretarial work, and though these occupations are relatively skilled tasks, pay and career mobility within them is limited. $61(32.9 \%)$ of the respondents relate overall gender pay gap to differences in life choices such as marriage and childbearing. In terms of the marriage variable, historical norms indicate that marriage has a negative impact on female pays though times are changing. The regressions gave a positive marriage coefficient for both men and women probably due to recent social changes. For instance in older times, married women were not allowed to work. These laws are no longer there and societal expectation that a woman will quit her job when she gets married is gone. The net effect of the marriage and the children variables is negative.

\section{Discrimination}

The remaining proportion of the pay disparity that cannot be explained by differences in human capital variables or crowding is usually referred to as the residual. Becker (1993) suggests that the residual indicates pure "tastes" for discrimination.

Table 4 illustrates the results of multiple regression analysis of pay on gender and discrimination. This table reveals that discrimination contributes significantly to gender pay disparity. The data in Table 4 indicates that discriminations explains about $49 \%\left(R^{2}=.52^{* *}, p<.000\right)$ and stereotypes about $51 \%\left(R^{2}=.48 * *, p<.002\right)$ of the variance in pay differentials of the respondents. Table 4 also indicates that $51 \%\left(R^{2}=.51^{* *}, p<.004\right)$ of the variability in salary differential could be attributed to discrimination against females.

Table 4 The coefficient for the discriminatory effects of crowding on wages for both sexes.

$\begin{array}{lccccc}\text { Variable } & \underline{\mathrm{R}} & \mathrm{R} & \mathrm{R}^{2} & \mathrm{~F} & \mathrm{p} \text {-value } \\ \text { Discrimination } & .68^{* *} & .72 & .52 & 8.60 & .000 \\ \text { Stereotypes } & .65^{\star *} & .69 & .48 & 9.21 & .002 \\ \text { \% in the Occupation } & .55^{* *} & 67 & .51 & 8.89 & .004\end{array}$

The Nigerian work environment, is a reflection of the society at large which is still a male-dominated. Also females are relatively new to the work environment especially at managerial levels though there is a gradual increase in female employment even at the managerial level in the management of business organizations in Nigeria.

\section{Recommendations}

This paper recommends the reduction of the gender pay gap through initiatives that combat occupational segregation and 
address women's labour market segregation. Government policies should promote equal opportunities for males and females in the workplace by reducing the gender pay gap; increasing availability of quality, part-time work, introducing gender duty and ensuring career guidance that is free from gender stereotyping. Pay differences must be carefully monitored and pay measures benefiting low-paid occupations should be introduced to improve the incomesituation of females. The initiatives should seek support for female careerdevelopment through new measures on parental leave and care services, in particular increasingthe number of crèches and introducing parental leave periods reserved for fathers, in order to balance the distribution of family care obligations between men and women.Awareness raising initiatives among employers and the wider public should be supported to share experiences and develop strategies as well as sending gender equality delegations to schools, improving conditions at workplaces, facilitating the combination of parenting and working, and increasing investment in women's entrepreneurial activities. Legislative support for collective bargaining on gender equality should be considered and multi industry agreement on gender balance and gender occupational equality. Some have advocated for provisions for mandatory quotas for women in boardrooms, voluntary quotas for women in management, corporate governance codes to promote better representation of women in senior managements.Women must be encouraged into male occupations. The crowding effect causes society to produce too much of the outputs that uses "underpriced" female labour. Over production leads to a simple supply and demand dilemma for female labour so that when supply exceeds demand price falls even further.

There is need to clarify, streamline and enforce existing laws and regulations. Next is the issue of policy perceptions. There must therefore be concerted efforts to educate the public that the aim of quota policies is to "equalize" the fairness of the labour market and ensure a more efficient allocation of resources.

\section{Conclusion}

This study found that the effects of crowding discrimination, differences in individual characteristics account for the gender pay gap and that that labour market discrimination against females persists. Since economic growth is largely dependent on the wellbeing of women, improving the status of women is not simply about social justice and human rights but economic growth. Unequal treatments bring about inefficient allocation of resources. A nation's competitiveness is jeopardized when skilled workers from any segment are excluded arbitrarily from employment opportunities or prevented from working up to full potential because of discriminatory practices, hostile workplace environment, or unnecessary inflexible employment policies. Organizations who want to gain competitive edge and advantage cannot overlook necessary skills and experience merely because of gender. This is a principle underlying

efforts to attract a diverse work force.

\section{References}

Anderson, Deborah J, Melissa Binder, Kate Krause (2003).The Motherhood Pay Penalty Revisited: Experience, Heterogeneity, Work Effort, and Work-Schedule Flexibility. Industrial and Labor Relations Review, Vol. 56, No. 2, pp. 273-294.

Arrow, K. (2003) Higher education as a filter Journal of Public Economics 2: 193 - 216.

Becker, Gary S. (1993) Human Capital, 3rd ed. Chicago: University of Chicago Press, 1993.

Bergmann (1984) Bergman, Barbara R. "Occupational Segregation, Pays and Profits When Employers Discriminate by Race or Sex."Eastern Economic Journal.April 1974, 103-10.

Blau; Francine D., Marianne A. Ferber and Anne E. Winkler. (2001) The Economics of Women. Men.and Work, 3rd ed. Upper Saddle River, New Jersey: Prentice Hall

Blau, Francine D., and Lawrence M. Kahn. (2006). The U.S. gender pay gap in the1990s: Slowing convergence. Industrial and Labor Relations Review 60 (1): 45-65.

Bommer, W.(2003). Emotional Intelligence And Individual Performance: Evidence of Direct and Moderated Effects. Journal of Organizational Behavior, 28, 399-421.

Boushey, F.W. (2007) "Sex Differences in Pays and Employment: A Test of the Specific Capital Hypothesis." Economic Inquiry.Vol. 15, No.4, October 2007, pp. 523-38

Collinson and Collinson (2000) Collinson, David, David Knights, and Margaret Collinson.Managing to discriminate. London; New York: Routledge, ISBN 978-0-415-01817-3.

Correll, Shelley J., and Stephen Benard. (2007). Getting a job: Is there a motherhood penalty? American Journal of Sociology, $112(5), 1297-1338$.

Federal Office of Statistics (2005): Reports on Gender Statistics in Nigeria Educational System.

GAO (2008) Women's Earnings: Federal Agencies Should Better Monitor Their Performance in Enforcing Anti-Discrimination Laws. GAO-08-799, August 11, 2008. 
Gerhart, B., \& Rhymes, G. T. (1991). Employee compensation: Research and practice. In M. D. Dunnette\& L. M. Hough (Eds.), Handbook of industrial and organizational psychology (Vol. 3, 2nd ed., pp. 481-569). Palo Alto, CA: Consulting Psychologists Press.

Macpherson, David A. and Barry T. Hirsch. "Pays and Gender Composition: Why Do Women's Jobs Pay Less?" Journal of Labour Economics.Vol. 13, No.3.July 1995, pp.426-71.

Mason, S.E. (1995), "Gender Differences in Job Satisfaction," Journal of Social Psychology 153(2):143-51. Volume 8 (2004)

Smith, James P. and Michael P. Ward. (1994) "Women's Pays and Work in the Twentieth Century.".RAND, r-3119-nichd.

Organization for Economic Cooperation and Development OECD (2009) Women's Entrepreneurship Issues and Policies, Paris:OECD.

Organization for Economic Cooperation and Development OECD (2010) Concepts, measurement and trends.In Informal Normal? Towards Moreand Better Jobs in Developing Countries, Jutting and Laiglesia, eds. Paris:

Organization for Economic Cooperation and Development (OECD).

Folayan Ojo (1998): Human Resources Management Theory and Practice. Panaf, Lagos.

Okpara, J. (1997), "An Examination of the Relationship of Motivation Needs, Cultural Factors, and Job Satisfaction Among Managers in Selected Business Enterprises in Nigeria" unpublished doctoral dissertation, New York University, New York.

Olagbegi, B.O. \& B. A. Afolabi (2004),"Actual Women Situation in Nigeria,"http://www.wildafao.org/eng/article.php3?id_article=46

Oloko, O. (2002) Influence of unplanned versus planned factory locations on workers commitment to industrial employment in Nigeria, Socio-Economic planning science (vol.7) Pergamon Press Great Britain

Opeke, T. (2002), "Women and Work in Nigeria: Problems and Prospects," paper presented at the World's Women Congress, Department of Gender Studies and Development, Makerere University, Uganda, 21-26 July.

Soetan, F. (2002). "Gender Mainstreaming in the Workplace; An Analysis of the Nigerian Experience" A Paper Presented in a Work Solberg,C. and Laughlin, P (1995) ). Biology at Work:Rethinking Sexual Equality. Rutgers University Press. pp. 7374.

Sowell Y.N. (1984). A Threat Is in the Air: How Stereotypes Shape Intellectual Identity and Performance. American Psychologist, 52: 613-29.

Stevens, P, John M. McDowell, Larry D. Singell and James P. (1993) Cracks in the Glass Ceiling: Gender and Promotion in the Economics Profession. American Economic Review, Vol. 89, Iss. 2, pp. 392-396.

UNDP (2009) Human Development Report 1995, New York: Oxford University Press

UNDP (2010) Human Development Report 1995, New York: Oxford University Press

Virginia, M.C. (2001) "Does the level of occupational aggregation affect estimates of the gender pay gap?"Industrial and Labour Relations Review. Vol. 49, No.2. January 1996, pp. 317-329.

Weaver, C.N. (1998), "Relationships Among Pay, Race, Sex, Occupational Prestige, Supervision, Work Autonomy and Job Satisfaction in a National Sample," Personnel Psychology 30:437-45.

Williams, O.P. Stanley, Thomas 1., William D. Danko. (2010) Diversity in workers empowerment for competitive advantage in work organization.Paper presented at National Workshop on Human Resource Development, organized by Nigeria Institute of Personnel Management at Abuja, Nigeria, October.

Witt, L.A. (1992), "Gender and the Relationship Between Perceived Fairness of Pay or Promotion and Job Satisfaction," Journal of Applied Psychology 77(6):910-17. 